\title{
EXTENSION OF GENERALIZED STRONG DRAZIN INVERSE
}

\author{
DiJAnA Mosić* AND Honglin Zou
}

Abstract. As an extension of the generalized strong Drazin inverse, we present a new generalized inverse for Banach algebra elements based on a $g$-Drazin invertible element rather than on a quasinilpotent element in the definition of the generalized strong Drazin inverse. Because of that, our new inverse will be called an extended $g_{s}$-Drazin inverse. Some characterizations of this inverse are given using idempotents and tripotents. We also study extensions of Cline's formula to the case of extended $g s$-Drazin inverse. Applying these results, we introduce and investigate an extended $s$-Drazin inverse.

Mathematics subject classification (2020): 46H05, 46H99, 15A09.

Keywords and phrases: Generalized strong Drazin inverse, extended $g$-Drazin inverse, $g$-Drazin inverse, Cline's formula, Banach algebra.

\section{REFERENCES}

[1] S. Breaz, G. Cǎlugǎreanu, P. Danchev and T. Micu, Nil-clean matrix rings, Linear Algebra Appl. 439 (2013), 3115-3119.

[2] H. Chen, S. S. NABAVI ANd M. Sheibani, Strongly Drazin inverse in rings, Operators and Matrices 13, 2 (2019), 495-505.

[3] R. E. CLINE, An application of representation for the generalized inverse of a matrix, MRC Technical Report 592, 1965.

[4] P. DANCHEV, Strongly nil-clean corner rings, Bull. Iranian Math. Soc. 43, 5 (2017), 1333-1339.

[5] A. J. DiEsL, Nil clean rings, J. Algebra 383 (2013), 197-211.

[6] O. GÜRGÜN, Properties of generalized strongly Drazin invertible elements in general rings, Journal of Algebra and Its Applications 16, 11 (2017), 1750207 (13 pages).

[7] J. J. Koliha, A generalized Drazin inverse, Glasgow Math. J. 38 (1996), 367-381.

[8] T. KoşAN, Z. WANG AND Y. ZHou, Nil-clean and strongly nil-clean rings, Journal of Pure and Applied Algebra 220 (2016), 633-646.

[9] X. MARY, Characterizations of clean elements by means of outer inverses in rings and applications, Journal of Algebra and Its Applications 19, 07 (2020), 2050134.

[10] D. Mosić, A note on Cline's formula for the generalized Drazin inverse, Linear Multilinear Algebra 63, 6 (2015), 1106-1110.

[11] D. Mosić, Extended g-Drazin inverse in a Banach algebra, Bull. Malays. Math. Sci. Soc. 43, 1 (2020), 879-892.

[12] D. Mosić, Reverse order laws for the generalized strong Drazin inverses, Appl. Math. Comput. 284 (2016), 37-46.

[13] D. Mosić And D. S. DJordjević, Weighted generalized Drazin inverse in rings, Georgian Math. J. 23, 4 (2016), 587-594.

[14] Y. QIN, X. LIU AND J. BeníteZ, Some results on the symmetric representation of the generalized Drazin inverse in a Banach algebra, Symmetry 11, 1 (2019), 105; doi:10.3390/sym11010105.

[15] J. Robles, M. F. Martínez-Serrano And E. Dopazo, On the generalized Drazin inverse in Banach algebras in terms of the generalized Schur complement, Appl. Math. Comput. 284 (2016), 162-168.

[16] Z. WANG, A class of Drazin inverses in rings, Filomat 31, 6 (2017), 1781-1789.

[17] K. YAN AND X. C. FANG, Common properties of the operator products in local spectral theory, Acta Math. Sin. (Engl. Ser.) 31 (2015), 1715-1724. 
[18] K. Yan, Q. Zeng AND Y. ZhU, Generalized Jacobson's lemma for Drazin inverses and its applications, Linear Multilinear Algebra 68, 1 (2020), 81-93.

[19] Q. ZENG, Z. WU AND Y. WEN, New extensions of Cline's formula for generalized inverses, Filomat 31, 7 (2017), 1973-1980. 